(1) Medical Measures,

(2) Enforcement of repression and protection laws,

(3) Sex Education and

(4) Provision of Recreational facilities.

Dr. William H. Welch, of Johns Hopkins University, is president of the conference.

An attempt will be made to work out a feasible three-year program for each of the countries of the western hemisphere. Preliminary organization is in charge of Paul Popenoe. Headquarters of the conference are at 411 Eighteenth Street, N.W., Washington, D. C.

\section{DYE DIVISION OF THE AMERICAN CHEMICAL SOCIETY}

The Dye Division of the A. C. S., which had its inception first as a Dye Symposium then as a Dye Section, is now a duly organized part of the American Chemical Society. The division is undertaking to carry on regular and systematic work for the benefit of the dye industry of America in general; and the users of dyes, manufacturers of dyes, and dye chemists in particular, laying, of course, its especial emphasis upon the chemistry of dyes and dyeing.

It is the duty and the privilege of every chemist in America, who is interested in the chemistry, manufacture, or use of dyes, to enroll himself as a member of the American Chemical Society and its Dye Division, to attend and participate in the semi-annual meetings. The advantage will be mutual, both to the members and to the industry.

To enroll yourself in the division, write to the secretary, and also inform him if you have ready for presentation any paper on the manufacture or application of dyes and intermediates. Enclose the sum of $\$ 1.00$ as dues for 1920. The dues are for the expenses of the division, consisting mainly of postage and stationary. It is planned as soon as funds permit, to compile and distribute a directory of dye chemists who are registered in the Dye Division of the A. C. S.

The next meeting of the Dye Division will be at the fall meeting of the American Chemical Society, to be held in Chicago September
7 to 10,1920 . At that time it is expected that a number of dye concerns will come forward with papers of intensive scientific interest.

There has been some considerable feeling in the past that the concerns should keep all their research work secret, and that none of it could be revealed at such meetings without detriment. However, since every research laboratory turns out a large amount of work which is of very great scientific interest to the trade in general but may have no specific bearing on any process in particular, we may expect that a large number of papers will be presented of such a nature as to demand the attention of every dye laboratory.

Please plan to attend this meeting and inform the secretary of the title of any paper pertaining to the dye industry that you will have ready for presentation.

$$
\begin{aligned}
& \text { R. Norris Shreve, } \\
& \text { Secretary }
\end{aligned}
$$

\section{Fifth Avenue,} NEW YoRK CITY

\section{THE FEDERATED AMERICAN ENGINEERING SOCIETIES}

THE following invitation is being sent to engineering and allied technical organizations, asking them to become charter members of The Federated American Engineering Societies.

The joint conference committee of the American Society of Civil Engineers, the American Institute of Mining and Metallurgical Engineers, the American Society of Mechanical Engineers, and the American Institute of Electrical Engineers, acting as the ad interim committee in accordance with the authorization of the organizing conference held in Washington, D. C., June $3-4,1920$, extends to your organization a cordial invitation to become a charter member of The Federated American Engineering Societies, and to appoint delegates to the first meeting of the American Engineering Council, of which due notice will be given, to be held in the fall of this year.

There has been previously sent to you an abstract of the minutes of the organizing conference, at which there were in attendance 140 delegates, representing 71 engineering and allied technical organizations. It was the unanimous opinion of 